\title{
Telecommunications and economic development: A case study of the district of Algoma, northern Ontario
}

\begin{abstract}
Randy Sweetnam, Ec.D.
The deployment of telecommunications infrastructure as a means of creating economic development opportunities and employment is a high priority for the Federal and Ontario governments, as well as the Algoma District Community Network (ADnet). This paper intends to examine and analyze the policy goals of both Canada and Ontario with respect to telecommunications and economic development in the Algoma District. Through an examination of potential users of telecommunications infrastructure, policies at each level of government and funding programs this paper will examine the Algoma experience in relation to meeting their objectives, specifically the economic development objective. The paper will conclude with recommendations with respect to this policy deficiency.
\end{abstract}

Keywords: telecommunications, infrastructure, policy, Algoma District Community Network (ADnet)

\section{Introduction}

The deployment of telecommunications infrastructure as a means of creating economic development opportunities and employment is a high priority for the Federal and Ontario governments, as well as the Algoma District Community Network (ADnet). This paper intends to examine and analyze the policy goals of both Canada and Ontario with respect to telecommunications and economic development in the Algoma District. Specifically, the paper will examine the development of the Algoma District Community Network and its economic development initiatives.

The examination will begin by reviewing the potential users of telecommunications infrastructure and some aspects of the marketplace where the new technology is being introduced. This examination is intended to identify constituencies (potential user groups) that will create the economic development opportunities. In the rapidly changing knowledge-based economy, there is a need to identify "convergence" of several fields, including telecommunications. The rationale for a particular focus on telecommunications policy is the high capital cost of the telecommunications component and the need by both levels of government to rationalize the capital infrastructure build based on economic development opportunities. 
The paper will then examine the policies and the frameworks at each level of government. The policies at each level of government are comprehensive and are further compounded by the interrelated and generally complementary nature of the policies between the two levels of government.

The next step will be to review the current funding programs in relation to the policies as well as the current activities as a means of examining the ADnet experience. The objective is to examine the Algoma experience in relation to meeting the objectives of the policies and funding programs, specifically the economic development objective. The continual upgrading of the programs, which are the implementation instruments of those policies, further complicates this examination. Because of the continual new financial investment in policies related to the knowledge-based economy, this paper is expected to have a short shelf life. It does however provide a reference point for examination of this case study.

The paper will also summarize the policies and their objectives in the ADnet experience and identify a constituency that this program is intended to address but does not as yet. The paper will conclude with recommendations with respect to this policy deficiency.

\section{Examining the users: Market place hype or reality?}

The super information highway is billed as:

1. A means of leveling the playing field between urban and rural Canada,

2. Introducing efficiencies of information dissemination with greater speed,

3. Providing new information sources to the workplace and the home,

4. Providing new services, such as security monitoring, remote command and information retrieval.

This section examines the context in which the constituencies are introduced to the information highway in Algoma District. In short, the constituency groups are flooded with market hype about solution delivery and in reality, the technology is not easy to use, nor inexpensive.

There is substantial market hype about the simplicity of the information highway and its benefits. One of the problems associated with the introduction (and associated benefits) of a major new technological development is the oftentimes contradictory goals of keeping the marketing message simple, while at the same time keeping it complete and accurate. 
As is the case in the introduction of many new technological developments, the super information highway message is not particularly accurate in its definitions. The development of the super information highway is the convergence of telecommunications, computing and information technologies. These terms are often interchanged in their use. There is a major learning curve associated with acquiring the skills to manage the new technologies. Sorting the message from the hype adds to the management learning curve, leaving some level of confusion in the acceptance of the technologies. In addition, the benefits have been identified as both positive and negative, leaving arguments available for those who are resistant to change. This paper is focussed on one of the three technologies of the super information highway, telecommunications. The rationale for this focus on telecommunications (as opposed to computing technology or information technology) is the high capital cost of this component and the policy developments of both levels of government to rationalize the capital infrastructure built based on economic development opportunities. However, it is impossible to separate the three components at the implementation stage given that economic development initiatives and business cases are dependent on software application use.

There is need to define the basic components of the technologies. Telecommunication at its most basic level is electronic messages from a terminal through a medium (normally a cable) which ends at another terminal. The terminals could be a phone, fax, computer, or other device.

Only after this most basic definition, do we start to add a few of the complexities to the definition of telecommunications; such as how many terminals receive the message, where are they located, how fast is the message delivered, and is it a closed or open network. Then, we add the other components of computing and information technology; for example use of an extranet, intranet or the internet, what application function is used, i.e. voice, data, e-mail, ftp, browsing, chat, telnet, EDI, videoconferencing, how is the information stored. The list goes on.

There is a lot of market hype (both positive and negative) about telecommunication technology, computing technology, information technology and the convergence of these three very distinct components of the super information highway. On the other hand, there are legitimate business efficiencies obtained with the introduction of these technologies in the workplace. Proponents of telecommunications development, who have acquired skills in the converging technologies, need to be reminded that for many, use of the Internet is still cumbersome, clumsy and confusing. This is particularly accurate when one considers the fact that for simple Internet uses such as the world wide web and e-mail, these activities can be incorporated into a common telephone and do not require the power of a typical desktop computer. ${ }^{1}$ It is the confusion created by the complexity of the converging technologies that is creating the reluctance for some elements of society to adopt the innovations available. 
The outcome of this technology convergence is not as predictable as a simple technology. Take for instance the introduction of the fax machine as a technology. It was not that complex (although some modes, such as mass faxing, fax on demand and half-toning could be complex) and the benefit of transmitting hard paper copy was high. The technology while new, was relatively simple, coupling existing hardware technology with simple information technology output. It was a machine that acted like a phone and photocopier, (existing technology), the information was a known quantity (what you put in one end came out the other) and the benefits were easily measurable (hard copy instantly delivered by wire rather than physical mail delivery).

Ten years later, the workplace is being asked to learn some level of computer skills (configuration and job-specific application use), information technology skills (data management and Internet development) and telecommunications skills (network routing). This is not a seamless or user-friendly activity and the role between technician and end-user is often not clearly defined. In reality, smaller organizations and businesses are relying on untrained or selftaught existing staff to lead in the use of telecommunications technology. While there are those who embrace the technology, there are those who resist it.

The positive hype refers mostly to the economic development opportunities, the levelling of the playing field between urban and rural areas and the enabling of the less powerful. Those who have control, or have a vested interest in, and/or can utilise the converging technologies foster the hype. ${ }^{2}$ The negative aspects tend to centre around the metaphysical issue of technology spiralling out of control, the content and censorship issues, accessibility and accountability and information overload. There are a number of other issues raised by communication theorists as it relates to the Internet and not to the more common voice and fax data

In fact, telecommunication in and of itself is no more than the connecting wire described above. Some telecommunication technology, with economic development potential, is simple and relatively user-friendly. Take the example of the point-of-sale swipe card technology.

Electronic swiping is not significantly different that the old mechanical swipe machine method. The fact that the swipe machine is connected to a modem/telephone line, electrical power, computer data banks and other information technology is irrelevant. It is not seen by the user (except when down) and the benefit is high, immediate or timely fund transfer to the retailer.

The issue in this intergovernmental policy framework is that these telecommunication policies and funding programs provide a problem definition, a set of goals and a set of instruments for those who embrace the technology. However, there is a problem emerging in the social side of

\footnotetext{
${ }^{1}$ Bell Canada, Press Release, Bell Canada launches e-mail access on the VISTA 350, introduces new generation VISTA 450, Hamilton, December 161998.

${ }^{2}$ The economies of North America, Europe and the Far East, as well as their respective political institutions are riding a wave of success based on information technology markets.
} 
the technology development. There are those who are resistant to change to a knowledgebased economy for a variety of reasons. The problem definition has not accounted for this demographic. This deficiency might not have been significant except that in the ADnet experience, this demographic represented a constituency of small business and public services where significant efficiencies and job creation could be achieved.

From September 1998, to February 1999, this author interviewed many telecommunication users from a variety of sectors. These were organizations that had been identified as existing or potential users of telecommunications for economic development or business efficiency opportunities.

For purposes of this paper the constituency groups can be classified into three categories. The first category is those organizations that are eager to adopt the technology and have the capability to implement it. The second category is those organizations that are eager or at least prepared to adopt the technology but have not yet developed the capability to implement it. The third category is those organizations that are not eager to adopt the technology and it goes without saying they have not developed the capability to implement it.

Within groups one and two, there are varying levels of readiness, but for the most part there is acceptance, even eagerness for the opportunities. However, within the third group, there are individuals who are prepared to share their reluctance to adopt change. They share observations that extra energy will be required to teach themselves these new technologies, while still maintaining their current level of performance. Among this group there is scepticism that the level of predicted efficiencies would be achieved.

In the Algoma District, with its low population density and vast expanse, the participation of virtually every group is necessary to make the business case to access the funding programs to develop the infrastructure. ${ }^{3}$

\section{The government policies environment}

As indicated, the development of telecommunications infrastructure is a high priority for both the Federal and Ontario governments. This priority is demonstrated in their respective funding commitments in 1998-99 and 1999-2000. The Federal policy is explained in a comprehensive policy document entitled 'Connecting Canadians ${ }^{4}$. This policy contains goals such as economic development, socio/cultural goals and rural access. The Provincial goals are expressed in terms of objectives: "projects must also achieve one or more of the following objectives: improve access to the information highway, offer new services, improved productivity or cost-savings,

\footnotetext{
${ }^{3}$ This observation would apply throughout Northern Ontario.

${ }^{4}$ Industry Canada, Policy on Connecting Canadians,

http://www.ic.gc.ca/cmb/welcomeic.nsf/558d636590992942852564880052155b/bd8045bd3b2c8db48525673e007089fc
} 
enhance business profitability and/or have a positive economic impact such as new business activity and jobs. Projects must not compete with existing private sector initiatives." 5 In both cases, economic development is closely tied to telecommunications development. The notion of modern telecommunications and economic development initiatives date back at least to March, 1994, in a paper delivered in Buenos Aires by Hugette Labelle, then President of the Canadian International Development Agency. ${ }^{6}$

At the outset, it should be said that the federal and provincial governments are to be commended for the comprehensive and inter-related nature of these policy initiatives. This is not to say that the policies are complete, or completely comprehensive. That is a point to be addressed in the conclusion of this paper. Indeed, this lack of comprehensiveness is the point made in an article in the National Post by David Akin. ${ }^{7}$ But first, it is necessary to state the context of the policy framework.

The federal policy is a continuation of one of Canada's major international market niches, telecommunications technology. Clearly one of the outcomes of this policy is to jump start Canada's participation in the emerging global marketplace, building on an existing strength. Its focus is connectivity, especially to rural populations, volunteer organizations, schools, and similar organizations.

While the provincial objectives (policies) are developed separately, they build on the federal policy by providing capital funding programs for infrastructure development. The Telecommunications Access Partnership (TAP) program and the Northern Ontario Heritage Fund Corporation (NOHFC) program assumes the need for building telecommunication backbone capability, with some emphasis on rural and remote Ontario. The policy objectives as expressed by the funding programs assume connectivity capability, or the ability to overcome infrastructure gaps at a reasonable cost. The programs also assume a local solution model, using the Community Broadband Network (CBN) mechanism in the same way as the Province uses local government as a solution mechanism for local activities.

In examining the telecommunications component of the general policy framework of 'wiring' Canada and Ontario. Except where indicated, the policies of both levels of government will be considered complementary, since the goals are very similar. As Industry Canada Minister, John Manley writes, "We're not just helping individuals get connected, we're creating new opportunities for small and medium-sized businesses, and for rural and urban communities in every part of Canada." 8

\footnotetext{
${ }^{5}$ Northern Ontario Heritage Fund Corporation published criteria for telecommunications pilot projects, dated February 1998, at http://www.gov.on.ca/MNDM/nohfc/pilote.htm

${ }^{6}$ CIDA, Telecommunications and Sustainable Development, Hugette Labelle, President CIDA, March, 1994 at http://www.acdicida.gc/ca/cida_ind.nsf/

${ }^{7}$ National Post, Canada $10^{\text {th }}$ on information highway study: PM wants to be No. 1, April 6, 1999, p. A1.

${ }^{8}$ Industry Canada Minister John Manley, September 8, 1998, at http://www.connect.gc.ca/English/Initiative/IntroductionENG/index.html
} 
There is a need to clarify some of the definitions and examine the technology convergence. This technology revolution is coming at a time when the largest demographic component of Canadian society is on the edge of retirement. This poses a certain challenge with that segment of the demographic that is not accepting of change at this point in their professional careers. The change is also coming at a time when many organizations, in particular public sector organizations, are squeezed for human and financial resources. Acquiring additional funds for computer consulting and equipment for management of technology change can prove difficult to impossible. The Community Broadband Network model is particularly useful in this instance because it provides a forum for the exchange of ideas and mutual assistance.

To summarize the policy context, the federal and provincial governments have established explicit or implicit policy documents, with funding programs to undertake economic development initiatives through connectivity to telecommunications networks. The province is using the Algoma Community Broadband Network model (a local co-operative of users) to deliver local solutions.

\section{Current funding programs}

There are a number of funding programs related to the knowledge-based economy. The programs are growing in number and so is the level of funding commitment. Programs are available from both the federal and provincial governments. The significant difference is the federal programs are not concerned with building backbone in provincial jurisdictions. ${ }^{9}$

The programs are listed with descriptions provided by the program marketing material.

Northern Ontario heritage fund: Telecommunications pilot projects

The Northern Ontario Heritage Fund Corporation (NOHFC) is seeking expressions of interest to undertake telecommunications pilot projects in Northern Ontario. It is expected that these pilot projects will begin development over the next year and will be distributed throughout Northern Ontario.

Preference will be given to projects that:

- develop shared networks that address the needs of a wide variety of partners

- improve ways of doing business in the private sector and/or public sector

- help applicants become more competitive and efficient through the application of communications technology

\footnotetext{
${ }^{9}$ This may have changed with the availability of CA*net 3 as the backbone for the five Northern Ontario nodes.
} 
- $\quad$ overcome the problems of distance, small populations, cost of service and other impediments

- remove access barriers to the Information Highway. ${ }^{10}$

\section{Telecommunications Access Partnerships (TAP)}

Telecommunications Access Partnerships provides assistance to encourage groups of users business sectors, the broader public sector, communities and entrepreneurs - to work together in innovative ways to develop and implement information highway projects.

\section{TAP Phase II}

On May 5, 1998 the Minister of Finance, the Honourable Ernie Eves announced in the 1998 Ontario Budget that the Government will be providing \$30 million over the next three years for investment in Information Highway projects through TAP.

Benefits to Ontarians: TAP is intended to do the following:

- help sectors, communities and entrepreneurs use the information highway to become more efficient and competitive;

- help broader public sector organizations find better ways to deliver services and to collect, use and share information;

- improve the ability of communities and regions to retain and attract business through expanded access to the information highway and an improved telecommunications infrastructure;

- increase the capacity of Ontario's research and development communities and information industries to develop and test new products to take advantage of the information highway;

- strengthen Ontario's image as a leading, competitive information highway jurisdiction.

Three priorities

High priority will be given to funding projects that will:

- develop shared regional/community networks that involve broad-based public and private sector partnerships. These networks should improve access to advanced information highway applications and services for residents, businesses and public bodies, particularly in rural areas and small communities;

\footnotetext{
${ }^{10}$ http://www.gov.on.ca/MNDM/nohfc/pilote.htm, March 7, 1999.
} 
- develop advanced network initiatives that demonstrate the potential for significant improvements in the ways of doing business in various sectors, including the broader public sector;

- develop leading-edge network initiatives that support or link major R \& D activities. They should also contribute to the development of a province-wide, shared backbone network equal to or better than those in other jurisdictions throughout the world. ${ }^{11}$

CAP

CAP, Industry Canada’s Community Access Program works with rural Canadian communities to take advantage of new communication technologies. CAP's goal is to foster economic, social, and cultural growth in Canada. All CAP sites are community-based, with a variety of provincial, territorial, and national partnerships supporting these local initiatives. Also helping to guide the program are Industry Canada's regional CAP reps, CAP's Provincial/Territorial Review Committees, Special Provincial Agencies, and the CAP National Advisory Committee. ${ }^{12}$

To March 1999, four thousand rural projects have been activated.

\section{Cap Upgrade}

It is anticipated that the CAP program will be funding 5,000 urban locations in Canada. If intergovernmental agreements can be negotiated, rural sites will be eligible for up to $\$ 40,000$ dollars. Existing rural sites that have received up to $\$ 30,000$ in matching funds, will be eligible for the top-up to $\$ 40,000$ in matching funds.

\section{FEDNOR}

FedNor recognises that access to a modern telecommunications infrastructure is a key ingredient to business competitiveness. Developing the full benefits and commercial advantages of the information highway requires a reliable electronic backbone across the region. Currently there are wide variances in the telecommunications services available in the communities of Northern Ontario.

FedNor's objective is to ensure that all areas of Northern Ontario have access to the telecommunications infrastructure and benefit from the opportunities of the Information Highway.

After compiling an inventory of telecommunications services in each Northern Ontario

\footnotetext{
${ }^{11}$ http://www.networks-ontario.com/tap/e-telecom_access.html, March 7, 1999.

${ }^{12}$ http://cap.unb.ca/aboutcap/info/ March 7, 1999.
} 
community, FedNor began supporting community- based groups to develop business cases that would encourage service providers to upgrade their equipment. All regions of Northern Ontario are currently involved in this process. FedNor continues to explore other opportunities to support telecommunications objectives in Northern Ontario. ${ }^{13}$

\section{Other}

There are other funding programs that are indirectly associated with the specific undertaking in Algoma District. That is not to suggest that they are irrelevant. Indeed, it is expected that these programs may provide the potential to introduce many of the technology transfer requirements into the Algoma District, improve efficiencies, or provide seed money to a number of community-based initiatives.

Some examples of these programs include the following:

\section{Human Resources Development Canada (HRDC)}

This federal agency provides staff capability through several of their programs. ADnet has already made use of one such HRDC program by acquiring three staff to undertake the program management. ADnet was required to maintain a pace of activity that was not consistent with volunteer participation alone. The volunteers now provide policy management, while the staff provides program management.

\section{Bell Canada Fund}

Bell Canada has provided $\$ 800,000$ over three years for community-based telecommunications projects.

\section{Trillium Foundation}

This provincial program offers volunteer organizations an opportunity to disseminate information about their particular organizations. This would include information concerning services and activities, recruitment, fund-raising, events and a variety of other types on information in a cost-effective manner. But more, this program offers these organizations an opportunity to develop collective and co-operative efficiencies through use of central servers and similar technologies.

Volunteer Network (VolNet)

\footnotetext{
${ }^{13}$ http://strategis.ic.gc.ca/SSG/fn00230e.html March 7, 1999.
} 
This federal program offers connectivity to volunteer organizations. The relevancy of this program is that it will not only provide efficiencies in the volunteer sector, it is a venue for small business owners and public agency workers to see a demonstration of the technology.

\section{Ontario Ministry of Agriculture, Food and Rural Affairs (OMAFRA)}

The Ontario Ministry of Agriculture, Food and Rural Affairs has a number of programs that may be used for technology transfer, telecommunications development, economic development initiatives and particularly programs related to rural youth. Rural Job Strategy, in particular, is a useful program for CAP sites.

\section{Network 2000}

The Province financed connectivity and interlibrary loan between the libraries of Ontario. This program has been central to the economic development role now being assigned to the libraries in Ontario.

In a separate development, the federal government has added \$2.4 million dollars through the Community Access Program to the $\$ 2.5$ million dollars already spent by Ontario.

\section{Northern Ontario's initiative}

When the Northern Ontario Heritage Fund established a telecommunications pilot project fund with up to \$30 million dollars, the five regions in Northern Ontario agreed in April 1998, to coordinate telecommunications development throughout Northern Ontario. The five regions are in the Timmins area (NEOnet), North Bay/Nipissing (NIPnet), Sudbury/Manitoulin/Parry Sound (NetCentral), Sault Ste. Marie/Algoma (ADnet) and Northwestern Ontario (807 Northwest). The five regions are to be connected through an upper-tier, separate organization and funding submission. This pan-Northern Ontario submission was reorganized in September 1998 and is referred to as the Northern Ontario Community Network (NOCN).

\section{Algoma district community network}

In April 1998, several groups within the Algoma District with immediate telecommunications needs and previous experience came together to discuss a District-wide initiative. The plan was to submit an application to Heritage Fund for the first of two rounds of funding. That first round application funding, in the amount of approximately $\$ 200,000$, was to hire a consulting firm to complete a telecommunications needs analysis and build a business plan for submission to the Heritage Fund. This second submission would be for both telecommunications infrastructure and computer application funding. Some of the funds would be used for application 
development on a sector basis. In this way, each sector would have an opportunity to establish protocols and look at application needs. (In addition, each sector would look at cross-sector protocols, as well as pan-Northern Ontario protocols through Northern Ontario Community Network). One of the activities of this sector development was to pool resources and offer each of the participants the benefit of each other's experience and expertise in application development. This approach is crucial to achieving the economic development objectives.

One of the staff positions developed by ADnet is specifically assigned the task of sector application development for economic objectives. This means bring the players of a particular sector together to identify common and individual needs. Four sectors have been identified to July 1999. They are the health sector, education sector, business sector and public channel sector.

In the health sector, funding has been approved for a satellite radiology centre in Sault Ste. Marie. This will involve bandwidth requirements for imaging and reduce the need for up to 400 people travelling from Sault Ste. Marie to Sudbury on a regular schedule throughout their treatment timeframe. This is an immediate need to undertake sector development.

One of the first application possibilities in the education sector is the new safe arrival policy issued by the Ministry of Education \& Training. It provides an opportunity to undertake an immediate solution application, since the solution delivery is required by September 1999.

The business sector will likely become many sectors. However, an immediate need is for all of the youth agencies to communicate with one another, using a common information database. This application solution may be undertaken quickly, again for delivery by September 1999.

The public channel sector includes the agencies that are seeking to provide web-based information about their agency, programs, services or events. Agencies such as the Algoma Training Board, Algoma District Information Network, Algoma.Net, the Sault Free-net, the Community Access Program sites and others would fall into this category.

The early membership of the group consisted of many of the public sector organizations, as well as community groups throughout the District, who are telecommunication users. The original list, as of April 1998, is attached at Appendix A. The importance of this list is to demonstrate the high calibre of membership at the outset. Included, as well are the additions to the list as of March 1999. The group was convened as a working group under the name of Algoma District Telecommunications Network (ADnet). It is now incorporated as Algoma District Community Network (ADnet). 
The status of the ADnet initiative, as of May 1999, is that the organization has established a governance model and is incorporated. It has hired three staff people under an HRDC funded initiative and has submitted the business plan to Heritage Fund. In addition, ADnet has contributed to the development of NOCN. ADnet has received funding from its members, FedNor, Heritage Fund and Human Resources Development Canada. However, ADnet is not yet in a position to complete an application for a TAP grant or the remaining grant opportunities identified above.

ADnet has four objectives. They are identified on the Internet at URL www.hiawatha.net/community/adnet. They are:

1. To develop high speed internet access at affordable cost.

2. To ensure high speed access to everyone throughout the District

3. To eliminate obstacles to telecommunications-based applications

4. Promote IT as an enabler of economic, social and cultural development initiatives

The last objective is the one of most interest to this paper. As an enabler of economic development initiatives, ADnet is co-ordinating educational sessions for members throughout the District on such subjects as e-commerce and business opportunities through computer applications and telecommunications.

Further, ADnet's study has established an existing, as well as a growing need for high-speed telecommunications for business applications. This is an important aspect of the business case for funding, as well as sustaining the community broadband network in the long-term. Extremely important to the ADnet business case is the large area and low population density of the region it serves. Given these two factors, each computer application opportunity is necessary to sustain the network. ADnet is much more sensitive to market forces than is a region that has a higher population density. The immediate business case can be achieved with existing users. The difficulty will be in acquiring the additional users to sustain the network in the long-term. The additional users will be those who are less prepared for telecommunications solutions.

As recently as mid 1998, the primary telco supplier in Algoma District was not convinced of a business case for supplying other than 56Kbps telephone line capability throughout the District outside the city of Sault Ste. Marie. In a public/private partnership, FedNor underwrote the telco's cost of implementation of frame relay capability, where it had been indicated that there was no business case. Both ADnet's and the telco's business case established the need and growth potential of a number of business opportunities in these locales.

The success of the ADnet initiative has lent credibility to the telecommunication and information technology development scenario in Algoma. Consequently two other initiatives have surfaced. 
One is a baseline study of information technology jobs throughout the District. The second is a feasibility study for an Innovation Centre in Sault Ste. Marie.

\section{Current activities of ADnet}

It is apparent that there are a number of concurrent activities underway in the Algoma District. It is not the intention to undertake an exhaustive listing, but to summarize principal activities.

A brief list follows:

- initial partnership arrangements and funding proposal to Heritage Fund by May, 1998

- initial funding to FedNor by June, 1998 for developmental study

- governance framework by August, 1998

- incorporation by December, 1998

- study completed by March, 1999 for submission to Heritage Fund

- from April 1998 to April 1999, the membership grew from the original nine to 21.

- April 1999, ADnet hires three staff.

- May 1999, Heritage Fund announces up to $\$ 16$ million dollars for telecommunications projects to the five nodes. ADnet's share is up to $\$ 2.7$ million dollars.

There are two major conferences that have been useful in ADnet's development. These conferences have been helpful in transferring knowledge and best practices, as well as affording opportunities to make useful contacts.

The first are the Community Broadband Network conferences held in April each year. In 1998, in Ottawa, the conference was successful in demonstrating success stories and what was necessary to achieve a certain level of activity. While it is TAP program-focussed and therefore applications focussed, it does provide direction recognising that ADnet's needs are initially more infrastructure-related. The April 1999 conference in Kitchener provided the first opportunity to identify trend development when compared with the activities of the first conference.

The second conference is the Canadian Libraries Association. In June 1998, there was a preconference seminar to the Canadian Library Association Annual Conference in Victoria, British Columbia. The seminar was entitled 'Libraries as Leaders in Community Economic Development. ${ }^{14}$ The papers from this conference were instrumental in developing a mechanism to critique some of the funding proposals for ADnet. This conference was particularly relevant, since in many cases it was the rural community library that was used to apply for Community Access Program (CAP) grants. In Algoma, the library undertook the original community training in conjunction with the Algoma school boards. The theme was developed further in 1999. The Canadian Libraries Association meeting in June 1999 was described as:

\footnotetext{
${ }^{14}$ http://www.asm-consultants.com/resources.htm
} 
"Get smart - economic development libraries and smart communities"

"A major international event for librarians, federal, provincial and municipal government representatives, economic development planners, the IT industry, public policy experts and groups working with information and smart communities in today's knowledge economy."15

The Canadian Rural Partnership offers rural Canadians an opportunity to dialogue about life and issues in rural Canada. The policy initiatives of many federal departments are examined through the process referred to as a "rural lens" and demonstrated benefits to rural Canadians are identified. This is applicable to the Algoma District and has certainly been of benefit.

The On-line Australia program is similar to the Connecting Canadians program at the national level. ${ }^{16}$ It is valuable to look at the approaches of other countries that are competing with Canada, recognising differences and similarities in demographics, economies and other criteria. On-line Australia was one of the countries that were report ed to have increased its lead as an "information economy powerhouse." ${ }^{17}$ This particular country was chosen as a comparison because of their increase in international positioning as well as the level and quality of participation by the Australians on the international listservs.

\section{Some policy gaps}

The telecommunications policies at the federal and provincial levels of government are comprehensive but are complicated by the inter-related, but generally complementary nature of the policies between the two levels of government. While both policy frameworks require high levels of local resource commitment, both government policy frameworks assist the development of infrastructure and applications solutions at the local level.

Remembering that the super highway is a convergence of several technologies that are still in their infancy helps to place the acceptance of the technology in some context. While there was no attempt within the current status assessment of the Algoma District feasibility study to identify or codify groups who would be resistant to change, some observations can be made. There are two groups that have been identified as resistant to change. There are those in the small and medium business sector and those in the public services sector. There are at least three subgroups involved in each sector. There are those who are waiting to embrace the technology opportunities, those who are not certain what it will do, but are willing to invest in it and those who are resistant to the change involved, whether or not they are aware of, or believe in the potential benefits.

\footnotetext{
${ }^{15} \mathrm{http}: / /$ www.asm-consultants.com/resources.htm

${ }^{16} \mathrm{http}: / /$ www.asm-consultants.com/toronto1.htm

${ }^{17}$ National Post, Canada $10^{\text {th }}$ on information highway study: PM wants to be No. 1, April 6, 1999, p. A1.
} 
There is abundant market hype in the introduction of the technology but the accruing benefits, which will have a significant impact on the economy and on job creation, require substantial investment in time, energy and resources. The current assessment evidence would suggest that the majority of potential users understand these benefits at this point in time. However, a significant group are not prepared to invest in, or do not understand the benefits of, telecommunications to economic development

Within these three subgroups, some are approaching retirement and do not wish to invest the time and energy so close to a point where these skills would no longer appear to be needed. For example, one municipal clerk indicated that retirement was months away and the municipality could begin looking for someone with information technology skills at that time. However, the incumbent was not interested in adding workload to an already burdensome task, which was compounded by provincial downloading.

Another group appears to find it too difficult to admit they have no knowledge of the technology and wouldn't ask, or attend a course. This situation has been identified through literacy surveys. In one extreme example a manager was interviewed and agreed with all of the potential benefits of the technology, but lacked any commitment to adopt it. It was later determined that although the individual was supposed to have information technology skills, in fact he did not. After becoming sensitive to this issue, an administrative officer and CEO were also found to have claimed skills when in fact they did not exist. It is important to note that this situation was discovered by just sampling a few of the potential telecommunications users who identified an interest in taking part in the needs assessment. The problem may be more widespread.

A third, but seemingly minor group, is resistant to new technology based on philosophy or ideology. This group is resistant to change associated with the industrial era, much less the information era. At a public rural meeting, one young adult female indicated that reliance on anything other than hand-labour skills and local community invited vulnerability to outside influences. Consequently, she was satisfied with the telephone party-line system, since she had no intention of purchasing a computer, much less computer networking outside the home. This is a successful, independent, small businessperson in the crafts and farm produce field. The exact numbers of those resistant to change are difficult to predict. The national figures for literacy and computer literacy, however, suggest the percentage is significant. Anecdotal evidence for the Algoma region also suggests the percentage is significant.

It is significant because every potential user of the network is crucial to the success of the business case of the network. As indicated earlier, because of low smaller population density and larger area, it is more difficult to sustain the network in Northern Ontario, given the prevailing market forces. In this situation each potential player has increased significance in the 
potential sustainability of the network. But as important is the cost-avoidance to taxpayers, the jobs to the economy and the support of a change in the cultural milieu.

The policy programs of both senior levels of government offer support for the technology, the computer applications and the training to those who are predisposed, or who are willing to accept change. It does not address those who are resistant to change. This issue is not a technology issue; it is a community development issue. Specifically, it is a "change agent" issue. Change agents identify and assess needs and address needs to achieve a positive conclusion. Addressing the learning curve and identifying economic development opportunities would be the objective of such a change agent activity.

There is a need for a policy analysis to address this change agent issue. First, there is a need to assess the extent of the challenge and analyze means for addressing it. The result might identify that the problem is not significant, or that it is unresolveable. Or, it might involve a special team or program available to provide assistance. This assistance might be available through a number of mechanisms. It might be through community development officers, although they do not exist in many jurisdictions, the libraries, although library staff will require significant training and extra resources, or through a Ministry, such as Northern Development \& Mines. On the other hand, it might involve support to local organizations, such as Community Development Corporations, or additional resources to the community-based networks. Finally, given the probable five-year time frame involved in preparing the communities, contracts with the private sector may be the solution to this issue. The mechanism would provide the speciality skills to not only assist those predisposed to technology change, but address the needs of those resistant to change.

\section{Summary}

This paper has examined the comprehensive policies and programs of both levels of government as they apply to the economic development opportunities through telecommunications development. The current needs assessment of the Algoma District served as a case study and identified a community development issue that is not addressed by the technology policy, namely - resistance to change amongst the population. The challenge is to assess the issue, analyse the value or cost of the issue and provide a means to rectify it. And this should be part of the policy agenda for both the Ontario and Federal governments.

This challenge will intensify as more and more technology is introduced in the information age. 


\section{Author's biography}

W. R. (Randy) Sweetnam is Principal of W.R.S. Communications. He is a graduate of Loyola University's Communications Studies Program and also has a Diploma in Computer Studies and a Certificate in Economic Development. Mr. Sweetnam has worked in the mass media markets of Montreal and Ottawa. He then spent eight years in Northern Labrador in the land claim negotiation process and then fifteen years in community economic development in Nova Scotia and Northern Ontario.

\section{Bibliography}

Algoma District Community Network (ADnet): Business Plan: Technological Assessment Study of The Algoma Region, Sault Ste. Marie, ONTARIO, March 1999.

Bell Canada Press Release: Bell Canada launches e-mail access on the VISTA 350, introduces new generation VISTA 450, Hamilton, December 161998.

Globe \& Mail, Technology Spending Spree Predicted, February 18, 1999, p. B8.

Government of Australia: On-line Australia, http://www.onlineaustralia.net.au/ March 1999.

Government of Ontario: Telecommunications Access Partnership, http://www.networksontario.com/tap/e-telecom_access.html, March 71999.

Government of Ontario: Ontario Budget, 1998, http://www.gov.on.ca/FIN/english/budeng.htm\#1998, May 5, 1998.

Industry Canada: Policy on Connecting Canadians, http://www.ic.gc.ca/cmb/welcomeic.nsf/558d636590992942852564880052155b/bd8045bd3b2c8 db48525673e007089fc, March 7, 1999.

Industry Canada: Community Access Program (CAP), http://cap.unb.ca/aboutcap/info/ March 7, 1999.

Industry Canada - FedNor: Getting Connected, http://strategis.ic.gc.ca/SSG/fn00230e.html March 7, 1999.

Labelle, Hugette, President: Telecommunications and Sustainable Development, Canadian International Development Agency (CIDA), http://www.acdi-cida.gc/ca/cida_ind.nsf, March 1994. 
National Post: Canada $10^{\text {th }}$ on information highway study: PM wants to be No. 1, April 6, 1999, p. A1.

Northern Ontario Heritage Fund Corporation: Telecommunications Pilot Projects, http://www.gov.on.ca/MNDM/nohfc/pilote.htm February 1998.

Appendix A: ADnet Members

\begin{tabular}{|c|c|c|}
\hline NO. & $\begin{array}{l}\text { Membership } \\
\text { Date }\end{array}$ & NAME \& ADDRESS \\
\hline \multicolumn{3}{|c|}{ Original members } \\
\hline 1. & May 28, 1998 & SSM Public Utilities Commission \\
\hline 2. & May 28, 1998 & Group Health Association \\
\hline 3. & May 29, 1998 & Huron-Superior Catholic District School Board \\
\hline 4. & May 31, 1998 & $\begin{array}{l}\text { Bruce Mines and Plummer Additional Union } \\
\text { Public Library/Algoma.Net }\end{array}$ \\
\hline 5. & June 08, 1998 & Community Living Algoma \\
\hline 6. & June 10, 1998 & Great Lakes Power Limited \\
\hline 7. & June 22, 1998 & Sault Area Hospitals \\
\hline 8. & July 03, 1998 & Algoma District Social Services Board \\
\hline 9. & July 17, 1998 & Mamaweswen, The North Shore Tribal Council \\
\hline 10. & August 05, 1998 & St. Joseph's Health Care \\
\hline \multirow[t]{2}{*}{11.} & August 06, 1998 & City of Sault Ste. Marie \\
\hline & Newer Members & \\
\hline 12. & August 10, 1998 & Sault Community Career Centre/ADIN \\
\hline 13. & August 11, 1998 & Algoma Business Computers \\
\hline 14. & August 24, 1998 & Economic Development Corporation - SSM \\
\hline 15. & November 30, 1998 & Northern Credit Union \\
\hline 16. & December 01, 1998 & Algoma District School Board \\
\hline 17. & December 03, 1998 & Community Development Corporation - SSM \\
\hline 18. & December 08, 1998 & Sault College \\
\hline
\end{tabular}

